\title{
Spatio-Temporal Analysis of Meteorological Drought in Cauvery Delta Zone of Tamil Nadu, India
}

\author{
S. Venkadesh ${ }^{\text {** }}$, S. Pazhanivelan ${ }^{2}$, K.P. Ragunath ${ }^{2}$, R. Kumaraperumal' ${ }^{2}$, \\ S. Panneerselvam ${ }^{1}$ and R. Sathy ${ }^{3}$ \\ ${ }^{1}$ Agro Climate Research Centre, TNAU, Coimbatore, Tamil Nadu, India \\ ${ }^{2}$ Department of Remote Sensing \& GIS, TNAU, Coimbatore, Tamil Nadu, India \\ ${ }^{3}$ Department of Physical Science and IT, TNAU, Coimbatore, Tamil Nadu, India
}

*Corresponding author:

\begin{tabular}{|c|c|}
\hline & $\mathbf{T}$ \\
\hline Keywords & \multirow{3}{*}{$\begin{array}{l}\text { Meteorological drought is a natural hazard that can occur under all climatic regimes. } \\
\text { Monitoring the drought is a vital and important part of predicting and analyzing drought } \\
\text { impacts. In the present study, monthly time series of rainfall data (1980-2016) from five } \\
\text { stations were used to derive SPI, particularly at 3-month time scales. This 3-month SPI } \\
\text { was interpolated to depict temporal patterns of meteorological drought and its severity } \\
\text { during } 2014 \text { and } 2016 \text { years. SPI was more efficient than departure in spatial analysis of } \\
\text { drought. An average of } 11 \text { years was negative departure on the SPI in north-east season } \\
\text { and also northern part of the station had recorded large deficient (-99\% to - } 60 \%) \text { of the } \\
\text { year drought condition. Rainfall deviations included both positive and negative deviations } \\
\text { and shown large variation in distribution of rainfall in all the stations. Hence, it was } \\
\text { concluded that integration and analysis of drought identified areas from these indices, help } \\
\text { in correctly identifying the region affected by drought. It was observed that SPI and } \\
\text { rainfall deviation have positive strong correlations in north-eastern part of the study area. }\end{array}$} \\
\hline Ar & \\
\hline & \\
\hline
\end{tabular}

\section{Introduction}

Drought is considered as a significant natural hazard which affecting several sectors in the economic and environmental across the world. It impacts almost all the hydrological cycle determinants beginning from rainfall and ending with streamflow in ground water structures (Tsakiris et al., 2013). Meteorological drought is the earliest specific event in the drought process. Rainfall is the primary driver of meteorological drought.
There are numerous indicators based on rainfall that are being used for drought monitoring (Smakhtin and Hughes, 2007).

However, Wilhite and Glantz (1985) have categorized drought into meteorological (lack of precipitatio $n$ ); hydrological (drying of surface water storage); agricultural (lack of root zone soil moisture) and socio-economic (lack of water supply for socio-economic purpose). Rainfall deviation from normal -a long term mean, is the most commonly used 
indicator for drought monitoring. In India, on the basis of rainfall deviations, four categories namely $\pm 20 \%$ deviation as normal, -20 to $60 \%$ deviations as deficit, $-60 \%$ and below as scanty, above $20 \%$ as excess are used to evaluate rainfall pattern across the country during the monsoon season (www.imd.gov.in) based on rainfall. In South Africa, less than $70 \%$ of normal precipitation is considered as drought and such a situation for two consecutive years indicates severe drought (Bruwer, 1990).

Although rainfall deviation from the longterm mean continues to be a widely adopted indicator for drought intensity assessment because of its simplicity, the application of this indicator is strongly limited by its inherent nature of dependence on mean. Rainfall deviations cannot be applied uniformly to different areas having different amounts of mean rainfall since a high rainfall area and a low rainfall area can have the same rainfall deviation for two different amounts of actual rainfall. Therefore, rainfall deviations across space and time need to be interpreted with utmost care.

The SPI can provide early warning of drought and help assess drought severity. Because of its standardization, it is particularly suited to compare drought conditions among different time periods, and regions with different climatic conditions (Bonaccorso et al., 2003). SPI is easy to calculate compared to the other indices, it is effective in providing early drought warning and drought damage control (Liu et al., 2012).

The present study analyses the response of seasonal SPI values to drought situation vis-avis comparison of SPI with actual rainfall and rainfall deviation from normal rainfall. The current research is being conducted for the Cauvery delta zone, where the north east monsoon concentration of rainfall is very high and Failure of the northeast monsoon in any year causes severe impact on the economy of these zones. Hence, to examine the applicability of various drought indices for monitor of meteorological drought characteristics. In this study, whether SPI can perform as a better indicator for drought assessment than widely adopted rainfall deviations in the Cauvery delta zone of Tamil Nadu.

\section{Materials and Methods}

\section{Study area}

The study focused on the Cauvery delta zones of Tamil Nadu, with an area of about 24,943 $\mathrm{km}^{2}$. The study has been carried out for Cauvery delta zones and lies between north latitudes of $10^{\circ} 00^{\prime}$ to $11^{\circ} 30^{\prime}$ ' to $13^{\circ} 35^{\prime}$ and $78^{\circ} 15^{\prime}$ to $79^{\circ} 45^{\prime}$ eastern longitudes with total geographical land area of 14.47 lakh ha. The highest temperature in the study area occurs during the pre-monsoon period (March-May) between $28^{\circ} \mathrm{C}$ and $40^{\circ} \mathrm{C}$. The region experiences a semi-arid to dry sub-humid climate semi-arid and dry sub-humid climate $r$ of Tamil Nadu with two distinct periods of rainfall seasons viz., south-west monsoon (June - September) and north-east monsoon (October - December). The annual rainfall of the zone is about $956.8 \mathrm{~mm}$ of which 48 per cent is through the north east monsoon and 32 per cent through the south west monsoon.

Since the state is entirely dependent on rains for recharging its water resources, monsoon failures lead to acute water scarcity and severe drought. The major crops are paddy, sugarcane, cotton, groundnut, sunflower, banana and ginger. Thanjavur district, which is known as "Rice Bowl" of Tamil Nadu, comes under this zone. Tamil Nadu is divided into seven agro-clima tic zones: north east, north west, west, southern, high rainfall, high altitude hilly, and Cauvery Delta (the most 
fertile agricultural zone). The map showing the selected are is given in Figure 1.

\section{Rainfall data}

Precipitation data were derived from monthly rainfall measurements for a period of 36 years (1980-2016). These monthly rainfall data were used to compute the SPI for five meteorological stations over Cauvery delta zones.

\section{Methodology}

The strategy adopted was to concentrate on using 3-month SPI data, to represent shorter, more intense droughts which could have immediate impacts on crop growth. Monthly SPI were acquired and decided to concentrate on monitoring temporal the spatial distribution of the most intense 3-month time scale of drought conditions especially for north east monsoon period from October to December. The percentage departure of the seasonal rainfall from the corresponding mean rainfall were calculated using IMD criteria. On the basis of percentage departure from the mean, the seasonal drought can be classified as excess, normal, deficient and scanty.

\section{Standardized Precipitation Index (SPI)}

The Standardized Precipitation Index (SPI) was developed by McKee et al., (1993) is a comparatively a main drought index which is based only on precipitation. The SPI states the possibility of occurring wet conditions in one or more-time balances and arid conditions at other time balances. The SPI allots all the precipitation observed a single numeric value, and will be associated with spatio-temporal data with significantly different climates. This spatial and temporal lets the SPI to be used in both the short-term agricultural and long-term hydrologica 1 applications and presented in table 1 .

\section{SPIij $=X i j-\mu i j / \sigma i j$}

Where, $\mathrm{Xij}$ is the monthly precipitation at the $\mathrm{i}^{\text {th }}$ rain-gauge station and $\mathrm{j}^{\text {th }}$ observation, Xim is its long-term precipitation mean and $\sigma$ is its standard deviation.

\section{Rainfall deviation}

Rainfall is the utmost significant indicator of analyzing the drought condition. A departure in percentage for the rainfall is calculated from its long-term averages (normal rainfall) and actual rainfall and it should be considered as a basis for declaring the drought. Rainfall anomaly has been computed for 2016 to indicate meteorological drought. The departure is calculated using the formula,

$\operatorname{Dep}(\%)=$ - $\begin{gathered}\text { Actual }- \text { Normal }) * 100 \\ \text { Normal }\end{gathered}$

The categories of the rainfall are made by calculating the departure percentage from the above given formula respectively in table 2 .

\section{Results and Discussion}

The analysis was focused on understanding the sensitivity of SPI to actual rainfall/rainfall deviation and the behavior of SPI in drought years. SPI is computed with help of five station daily rainfall data. It is evident from Figures 1, the analysis of SPI revealed that drought has occurred at different level of severity from 2013 and 2016 year.

The drought that happened in year of 2013 and 2016 was very severe rather than 2011 as explained by the SPI values that range from 0.6 to 2.00 and -1.02 to -2.00 respectively for aaduthurai, thalaignyaru, musiri and vallam. The result indicates that during 2016 years, there was rainfall deficit in the growing season and it, therefore, was the worst dry 
seasons. The large negative values of the SPI experienced at a few stations might be caused by large intra-seasonal variation in rainfall patterns and low mean seasonal precipitation.

On the other side, the SPI values in 2015 was ranged between 0.9 and 1.4 which indicates during this year there was less precipitation deficit. According to Standard Precipitation Index in 2013 many of the station's moderate rainfall deficit, but in 2014 it extends to southern region of the area and 2016 it converted as severely to extremely rainfall deficit. The Percentage departures of northeast monsoon rainfall in Cauvery delta zone of Tamil Nadu, histograms are presented in Figure 1-5, dry zone records averagely 11 years of $(-)$ negative departure over all stations. Guhathakurta (2003) has analyzed the district data during the all India normal monsoon years and found the probability of drought using percent of normal.

Table.1 Standard precipitation index (SPI) values categories

\begin{tabular}{|c|c|}
\hline SPI values & Categories \\
\hline$<-2$ & Extremely dry \\
\hline-1.99 to -1.5 & Severely dry \\
\hline-1.49 to -1.0 & Moderately dry \\
\hline-0.99 to 0 & Mildly dry \\
\hline 0 to 0.99 & Mildly wet \\
\hline 1.0 to 1.49 & Moderately wet \\
\hline 1.5 to 1.99 & Severely wet \\
\hline$>2.0$ & Extremely wet \\
\hline
\end{tabular}

Table.2 Rainfall departure categories

\begin{tabular}{|l|l|}
\hline-100 & No rainfall \\
\hline
\end{tabular}

\begin{tabular}{|c|c|}
\hline Deviation from Normal Rainfall $(\boldsymbol{\%})$ & Categories \\
\hline$>=20$ & Excess \\
\hline+19 to -19 & Normal \\
\hline-20 to -59 & Deficient \\
\hline-60 to -99 & Scanty \\
\hline
\end{tabular}


Fig.1 Location of rain gauges in the Cauvery delta zone

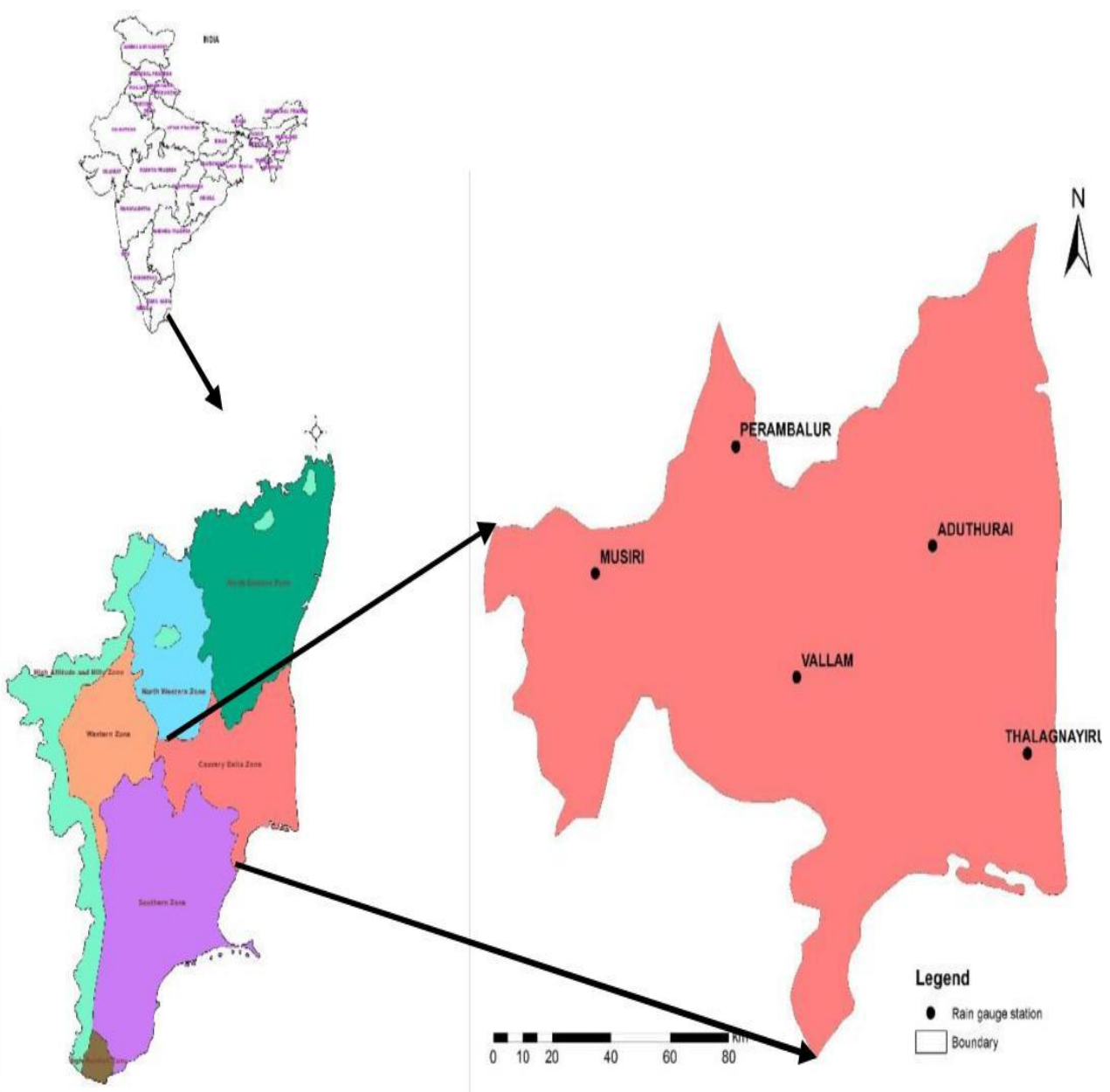

Fig.1-5 Temporal variation of Standard precipitation index values for 3-month

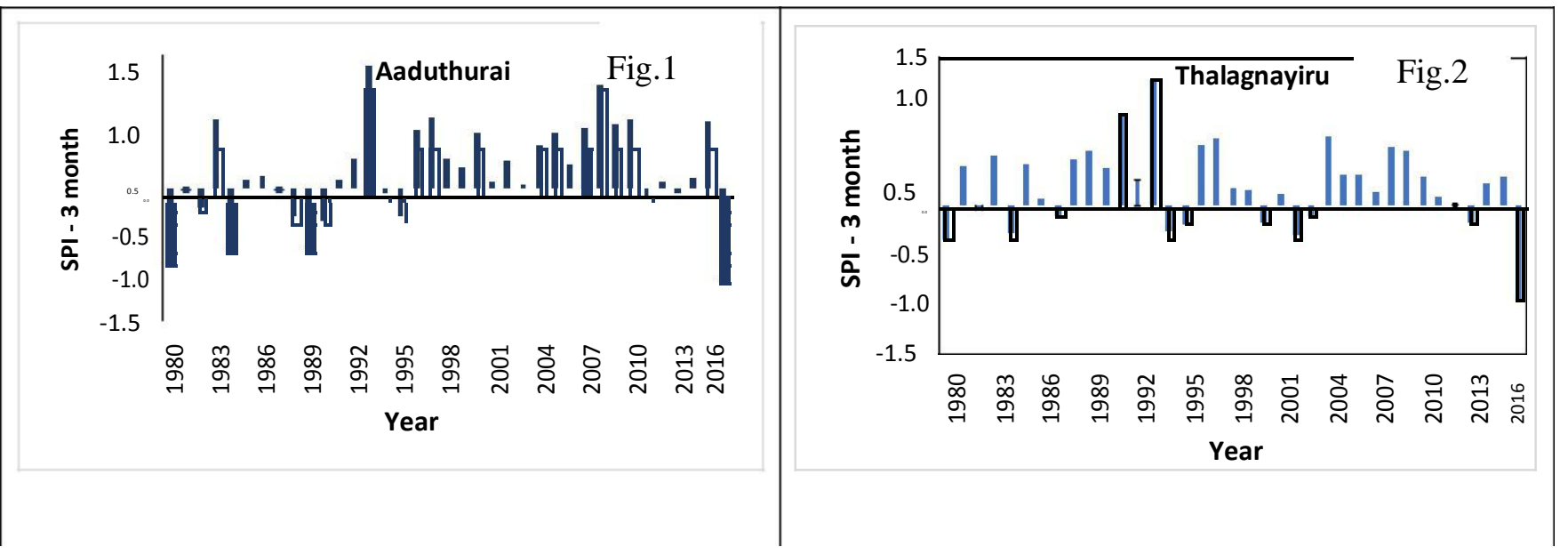



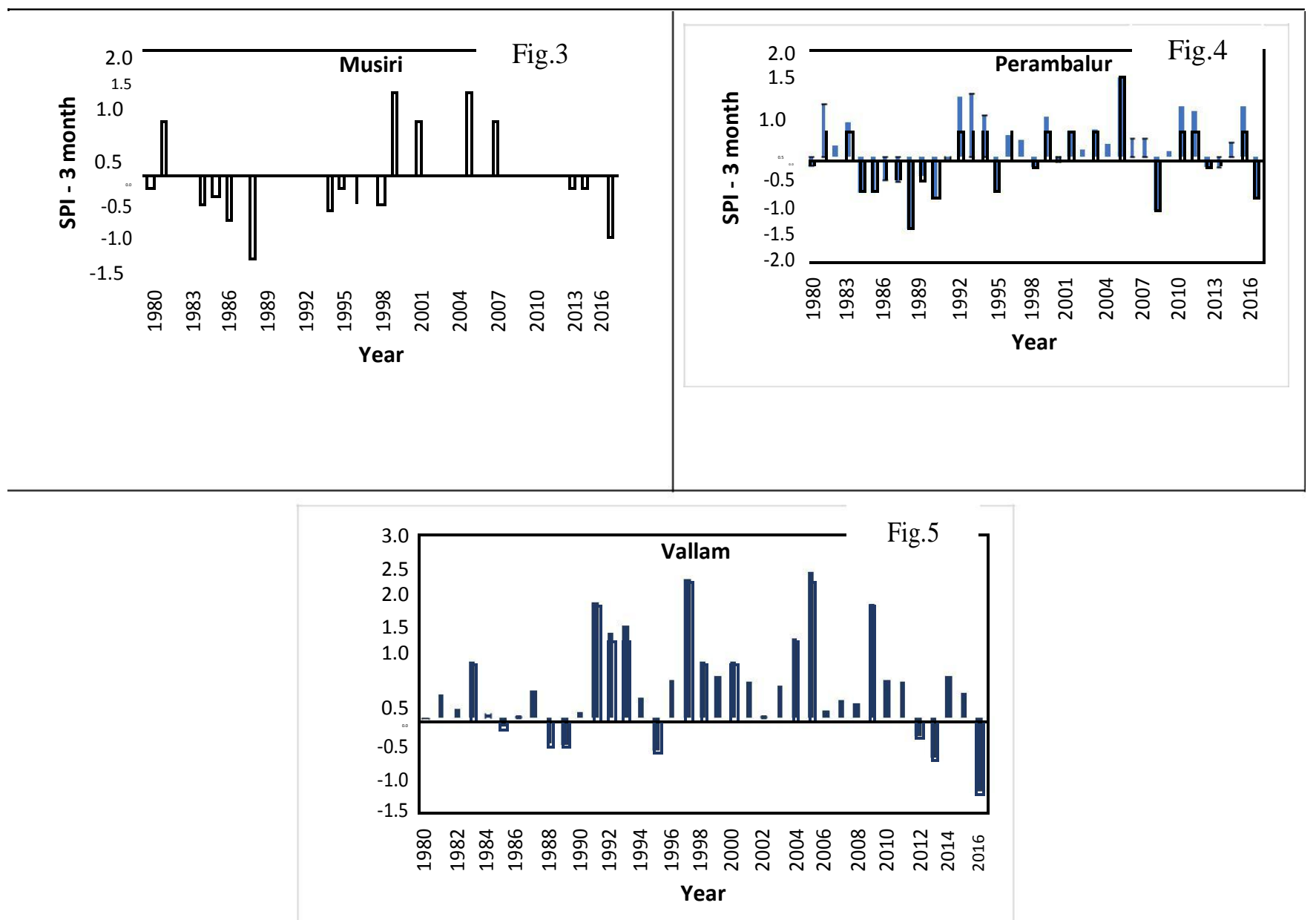

Fig.6 Spatial variation of rainfall departure of north east monsoon for CDZ

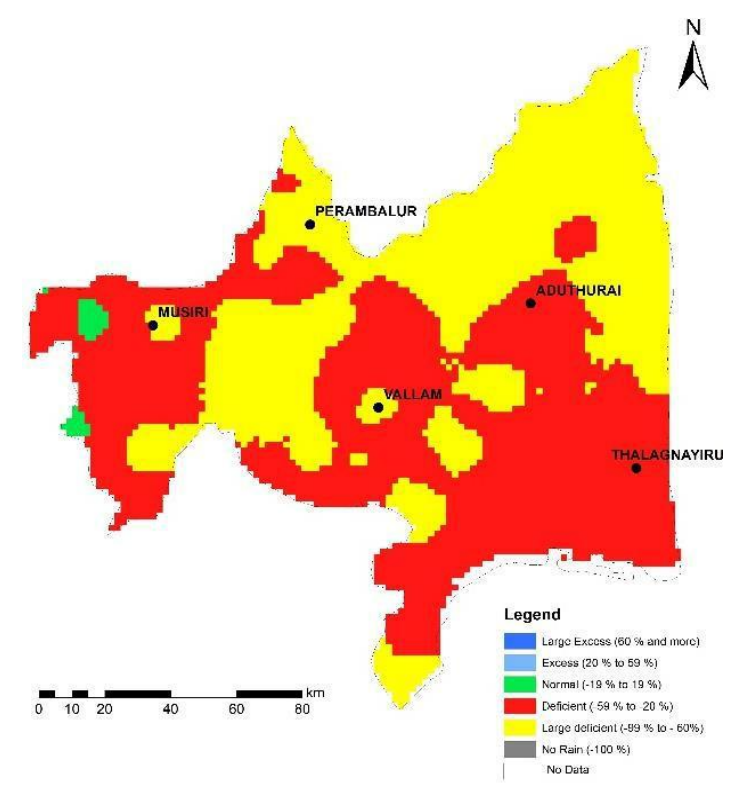


Furthermore, graphically, the patterns of rainfall deviation of north-east monsoon for five rain stations in Tamil Nadu and (Fig. 6) revealed that in 2016 the departure as low as Perambalur and most of the stations had deficient classes except some parts. These results further indicate that thalagnayiru was a more severe drought place where the SPI dropped to -1 only for three stations. This indicates that vallam was severely drought value -0.6. However, looking at the SPI patterns during the normal years, with the exception of a few stations the SPI values dominantly range between 0 and 1.8 , indicating moderately wet conditions. The standard deviation of 13.78 was adjusted and skewness in the data has been reduced from 0.48 to 0.80 .

The result of rainfall deviation on northern and southern part of the region have large deficient and deficient climatic condition and few amounts of area come under normal condition. Thus, there was a relation between SPI and negative rainfall deviations. The same period north western part, south eastern and southern part of the region is extremely and moderately dry condition. Therefore, the rainfall anomaly analysis concluded that southeastern region, north eastern region and southern region of the stations received low rainfall condition in that year.

Rainfall varies spatially and temporally throughout the whole Cauvery delta zone. On analyzing the rainfall for all the five stations in the state from 1980 to 2016, it was found that there is a large variation in rainfall especially in the years corresponding to 2014 and 2016 and highest deficient was found to be occurred in the coastal areas and normal rainfall in this time-period was seen in the central and northwestern part of the stations. The drought characteristic was observed using SPI and rainfall deviation for the meteorological drought to assess and monitor the drought condition in Cauvery delta zone, Tamil Nadu. From the study it concludes that an average 11 years are negative departure on the SPI in north-east season and also northern part of the zone were recorded large deficient (-99 \% to - $60 \%)$ of the year drought condition. Rainfall deviations included both positive and negative deviations and shown large variation in distribution of rainfall in all the stations. Therefore, SPI integrate with rainfall departures were better performed during the drought years.

\section{References}

Bonaccorso, B., Bordi, I., Cancelliere, A., Rossi, G. and Sutera, A. (2003). Spatial variability of drought: an analysis of SPI in Sicily. Water Resource Management 17, pp. 273-296.

Bruwer, J.J. (1990). Drought policy in the Republic of South Africa. In Proceedings of the SARCCUS Workshop on Drought, June 1989, Pretoria. Southern African Regiona 1 Commission for Conservation and Utilisation of the Soil, Pretoria, South Africa.

Guhathakurta P. (2003). Drought in districts of India during the recent all India normal monsoon years and its probability of occurrence. Mausam. 54, 542-545.

Liu, L., Hong, Y., Bednarczyk, C.N., Yong, B., Shafer, M.A., Riley, R., \& Hocker, J.E. (2012). Hydro-Climatological Drought Analyses and Projections Using Meteorological and Hydrological Drought Indices: A Case Study in Blue River Basin, Oklahoma.

McKee TB, Doesken NJ, Kleist J. (1993). The relationship of drought frequency and duration to time scales. Proceedings of the 8th Conference on Applied Climatology, American Meteorological Society, Boston: 179-184. 
Smakhtin VU, Hughes DA. (2007). Automated estimation and analysis of meteorological drought characteristics from monthly data. Environmental Modelling \& Software 22: 880-890.

Tsakiris G., Nalbantis I., Vangelis H., Verbeiren B., Huysmans M., Tychon B., Jacquemin I., Canters F., Vanderhaegen S., Engelen G., Poelmans L., De Becker P. and Batelaan O. (2013) A system-based paradigm of

drought analysis for operational management. Water Resources Management 27: 5281-5297.

Wilhite DA, Glantz MH. (1985). Understanding the drought phenomenon: the role of definitions. Water International 10: 111-120.

World Meteorological Organization. (1975). Drought and Agriculture. WMO Technical Note 138, WMO, Geneva, Switzerland.

\section{How to cite this article:}

Venkadesh, S., S. Pazhanivelan, K.P. Ragunath, R. Kumaraperumal, S. Panneerselvam and Sathy, R. 2019. Spatio-Temporal Analysis of Meteorological Drought in Cauvery Delta Zone of Tamil Nadu. Int.J.Curr.Microbiol.App.Sci. 8(06): 1356-1363.

doi: https://doi.org/10.20546/ijcmas.2019.806.164 